\title{
MASSAGE ABDOMINAL SEBAGAI TERAPI KOMPLEMENTER UNTUK MENJAGA KETERATURAN POLA ELIMINASI DEFEKASI PADA PASIEN DI RUANG ICU
}

\author{
Noferiana Widiyawati ${ }^{1}$, Fransisca anjar Rina Setyani ${ }^{2)}$, Emmelia Ratnawati ${ }^{3 \text { ) }}$ \\ ${ }^{1-3}$ STIKes Panti Rapih Yogyakarta
}

\begin{abstract}
ABSTRAK
Konstipasi adalah satu masalah yang sering terjadi pada pasien kritis yang dirawat di Ruang ICU. Hasil penelitian menunjukkan bahwa massage abdominal digunakan sebagai terapi komplementer untuk mencegah konstipasi dan mempermudah serta memperlancar pengeluaran feses. Tujuan dari penelitian ini adalah untuk mengetahui pengaruh massage abdominal terhadap pola defekasi pasien yang dirawat di Ruang ICU RS Panti Rapih Yogyakarta. Penelitian ini menggunakan desain penelitian quasi eksperimental post test only non equivalent control group. Teknik sampling menggunakan purposive sampling, yaitu sampel harus memenuhi kriteria inklusi dan eksklusi yang telah ditentukan oleh peneliti. Jumlah sampel yaitu 36 pasien yaitu pada kelompok intervensi $(n=18)$ dan kelompok kontrol $(n=18)$. Hasil penelitian menunjukkan bahwa rata-rata skor pola defekasi pada kelompok intervensi (1,33), lebih tinggi dibandingkan dengan kelompok kontrol $(0,67)$. Hasil uji statistik menggunakan uji non parametrik Mann-Whitney didapatkan hasil p-value 0,025 ( $\mathrm{p}<0,05)$, sehingga dapat disimpulkan ada pengaruh massage abdominal terhadap pola defekasi pada pasien yang dirawat di Ruang ICU RS Panti Rapih Yogyakarta. Terapi komplementer dengan teknik massage abdominal dapat menjadi salah satu metode untuk mengatasi masalah konstipasi pada pasien yang dirawat di ICU.
\end{abstract}

Kata kunci : ICU, konstipasi, massage abdominal

\begin{abstract}
ABSTRAK
Constipation is a problem that often occurs in critically ill patients admitted to the ICU. The results showed that abdominal massage was used as a complementary therapy to prevent constipation and facilitate and expedite expenditure. The purpose of this study was to determine the effect of abdominal massage on the pattern of defecation of patients treated in the ICU room at Panti Rapih Hospital, Yogyakarta. This study uses a post-test only non-equivalent control group quasi-experimental research design. The sampling technique used purposive sampling, namely the sample must meet the inclusion and exclusion criteria that have been determined by the researcher. The number of samples was 36 patients, namely in the intervention group $(n=18)$ and the control group $(n=18)$. The results showed that the average score of the pattern of defecation in the intervention group (1.33) was higher than the control group (0.67). The results of statistical tests using the non-parametric Mann-Whitney test showed a p-value of 0.025 ( $p<0.05)$, so it can be ascertained that there is an effect of abdominal massage on the pattern of defecation in patients treated in the ICU room at Panti Rapih Hospital, Yogyakarta. Complementary therapy with abdominal massage techniques can be a method to overcome the problem of constipation in patients treated in the ICU.
\end{abstract}

Keywords : ICU, constipation, massage abdominal 


\section{PENDAHULUAN}

Konstipasi adalah salah satu masalah yang sering dialami pasien kritis yang sedang diruang ICU, hal ini sesuai dengan penelitian Estri, dkk (2016). Menurut Estri, dkk (2016) kejadian konstipasi di ICU RS Panti Rapih terjadi setelah 3-4 hari perawatan dan setelah pemasangan alat bantu pernafasan ventilasi mekanik dan banyak terjadi pada usia lebih dari 40 tahun. Konstipasi adalah defekasi jarang atau defekasi dua kali per minggu dan kesulitan mengeluarkan feses (Lemone, et.al., 2016; Priscilla, dkk; Smeltzer, 2013).

Berdasarkan hasil penelitian McClurg (2017, dalam Hasmi, 2020), yaitu pengaruh terjadinya konstipasi adalah diet rendah serat, efek samping pengobatan, kelainan neurologis, kurang aktivitas, pemberian obat-obatan analgetika, narkotika, sedatif, antasida, dan anti depresan. Hal ini sesuai dengan penelitian Sharma, Kaur, dan Garg (2007, dalam Estri, dkk., 2016) yang mengatakan bahwa sebanyak $45,8 \%$ pasien ICU mengalami konstipasi karena pemberian terapi opioid dan $64,1 \%$ pasien ICU yang mengalami konstipasi karena tirah baring total.

Menurut penelitian Vincent dan Preiser (2015), konstipasi terjadi pada pasien di ICU yang terpasang alat ventilasi mekanik. Peralatan standar di ICU meliputi ventilasi mekanik untuk usaha bernafas melalui endotrakeal tube (ETT). Ventilator merupakan alat bantu pernafasan yang digunakan untuk pasien yang mengalami gagal nafas atau tidak mampu bernafas secara mandiri (Musliha, 2010 dalam Sari, Fauzan, Budiharto, 2015).

Penggunaan ventilator dengan positive end expiratory pressure (PEEP), efek samping pemberian sedasi, analgetika dan vasopressor akan mengakibatkan peningkatan tekanan intrathoraks sehingga mengakibatkan penurunan venus return dan penurunan curah jantung sehingga tubuh melakukan mekanisme kompensasi dengan menurunkan aliran darah ke sistem gastrointestinal sehingga terjadi penurunan motilitas gastrointestinal.

Menurut Azevedo dan Machado (2013), konstipasi menyebabkan distensi abdomen, ketidaknyamanan, dan gelisah sehingga menghambat diafragma serta menurunkan complience paru dan meningkatkan kerja pernafasan sehingga memperlama proses weaning ventilasi mekanik. Konstipasi harus dicegah dengan melihat banyaknya efek yang ditimbulkan dari konstipasi terutama bagi pasien yang dirawat di Ruang intensif.

Ada banyak cara yang dapat dilakukan untuk penatalaksanaan pencegahan atau penanganan masalah konstipasi, baik yang bersifat farmakologi ataupun non farmakologi. Salah satu tindakan non farmakologi yang dapat dilakukan untuk pencegahan konstipasi adalah massage abdominal. Hasil penelitian menunjukkan bahwa massage abdominal dapat digunakan sebagai terapi komplementer untuk pencegahan konstipasi.

Menurut Sinclair (2010), massage abdominal dapat mencegah terjadinya konstipasi dengan cara menstimulasi sistem saraf parasimpatis sehingga menurunkan tegangan otot abdomen sehingga meningkatkan motilitas sistem gastrointestinal, meningkatkan sekresi gastrointestinal dan merelaksasi sfingter sehingga melalui mekanisme kerja tersebut akan mempermudah dan memperlancar pengeluaran feses.

Menurut penelitian Ikaristi, Setyani dan Estri (2014), massage abdominal merupakan salah satu terapi komplementer yang dapat dilakukan untuk mencegah terjadinya konstipasi tanpa menimbulkan efek samping. Dalam penelitian Estri, dkk (2016) mengatakan bahwa massage abdominal dengan tehnik efflurage selama 7 menit tebukti efektif dalam mengatasi konstipasi yang disertai distensi abdomen. Menurut Lamas et al (2011), massage abdominal dengan tehnik efflurage merupakan terapi komplementer yang lebih efektif dan menimbulkan sensasi relaksasi dan meningkatkan kenyamanan bagi pasien. Menurut Kahraman dan Ozdemir (2015), mengatakan bahwa massage abdominal yang diberikan kepada pasien yang 
terintubasi di ICU dapat secara efektif dapat mengurangi volume sisa lambung dan distensi perut.

Hasil observasi pada 10 pasien yang dirawat di Ruang ICU RS Panti Rapih Yogyakarta sejak tanggal 16 Oktober - 22 Oktober 2020, ada 6 pasien mengalami konstipasi setelah menjalani perawatan di ICU selama dirawat 3-5 hari perawatan. Tujuan dari penelitian ini adalah mengidentifikasi pengaruh abdominal massage dalam upaya pencegahan konstipasi pada pasien yang dirawat di Ruang ICU.

\section{METODE PENELITIAN}

Penelitian ini menggunakan metode penelitian quasi eksperimental post test only non equivalent control group, yaitu membandingkan perbedaan pola eliminasi defekasi pasien pada kelompok intervensi (terapi standar dan massage abdominal) dengan kelompok kontrol (terapi standar) untuk pencegahan konstipasi pada pasien yang di rawat di ICU RS Panti Rapih Yogyakarta.

Massage abdominal adalah pemijatan yang dilakukan pada area perut dengan teknik efflurage. Pemijatan dilakukan pada area colon asenden, colon transversum dan colon desenden serta area intestinal secara sirkuler selama 15 menit dengan frekuensi 1 kali sehari selama 3 hari berturut-turut.

Populasi dalam penelitian ini adalah semua pasien yang dirawat di Ruang ICU

\section{HASIL DAN PEMBAHASAN}

Tabel 1. Pola Eliminasi Defekasi Kelompok Kontrol dan Intervensi Sebelum Menjalani Rawat Inap di Ruang ICU RS Panti Rapih Yogyakarta

\begin{tabular}{lcccc}
\multicolumn{2}{c}{$(\mathrm{n}=36)$} & \multicolumn{2}{c}{ Kelompok intervensi } \\
\hline \multirow{1}{*}{ Pola defekasi } & \multicolumn{2}{c}{ Kelompok kontrol } & $\mathrm{n}$ & $\%$ \\
\cline { 2 - 6 } & $\mathrm{n}$ & $\%, 1$ & 18 & 50 \\
Konstipasi & 13 & 36,1 & 0 & 0 \\
Tidak konstipasi & 5 & 13,9 & 18 & 50 \\
Total & 18 & 50,0 & & \\
\hline
\end{tabular}

Sumber: Data Primer, 2021

Dari tabel 1 menunjukkan bahwa seluruh responden mengalami konstipasi, yaitu sebesar $50 \quad \% \quad$ (18 responden) sebelum masuk Ruang Intensive Care Unit (ICU) pada kelompok intervensi dan pada kelompok kontrol lebih dari separuh
RS Panti Rapih Yogyakarta pada 29 Desember 2020 - 5 Februari 2021. Teknik sampling yang digunakan adalah purposive sampling, dengan kriteria inklusi yaitu pasien yang menyetujui dilakukan tindakan intervensi massage abdominal, pasien dengan hemodinamik stabil (MAP > 65, < 120, Nadi (60-110 X/menit), RR (14-20X/menit). Sedangkan kriteria eksklusi adalah pasien yang mendapat terapi laksativ, pasien dengan tumor abdomen, pasien dengan kasus ileus, pasien dengan trauma abdomen, pasien dengan perdarahan lambung maupun abdomen, pasien dengan sakit jatung post tindakan kateterisasi jantung atau tindakan PCI, pasien dengan kerusakan integritas kulit diperut, pasien dengan kehamilan.

Sampel yang dalam penelitian ini adalah 36 responden yang dibagi yaitu kelompok intervensi $(n=18)$ dan kelompok kontrol $(n=18)$. Peneliti melakukan observasi eliminasi defekasi pada kelompok kontrol dan kelompok intervensi setiap hari selama tiga hari. Instrumen penelitian telah dilakukan uji validitas dan mendapat rekomendasi dari dokter konsultan intensif care Rumah Sakit Panti Rapih Yogyakarta. Instrumen penelitian berisi untuk mengetahui konsistensi feces yang dikeluarkan setiap kali defekasi meliputi lembar observasi dan lembar wawancara pola eliminasi defekasi pasien serta bristol chart. responden mengalami konstipasi sebesar $36,1 \%$ (13 responden). Berdasarkan data diatas mayoritas pasien sebelum masuk ruang ICU mengalami konstipasi. Faktor yang mempengaruhi terjadinya konstipasi pada pasien yang jatuh pada kondisi kritis 
sebelum masuk ICU meliputi usia yang tua, kompleksitas penyakit, kondisi hemodinamik pasien yang tidak stabil, mobilisasi pasif yang lama dan lain sebagainya. Menurut Ikaristi, dkk. (2014), pasien yang dirawat di ruang ICU mengalami pembatasan aktivitas (bedrest) karena penurunan kondisi kesehatan, sehingga melemahkan aktivitas fisik yang dapat menurunkan tonusitas otot, yang diperlukan untuk mengeluarkan feses dari dalam rectum, hal ini dapat menurunkan fungsi otot abdominal yang menyebabkan konstipasi.

Tabel 2. Skor Pola Eliminasi Defekasi di Ruang ICU RS Panti Rapih Yogyakarta

\begin{tabular}{|c|c|c|c|c|}
\hline \multirow{2}{*}{ Kelompok } & \multicolumn{4}{|c|}{ Skor pola defekasi } \\
\hline & Mean & $\mathrm{n}$ & $\mathrm{SD}$ & Mean Diff \\
\hline Kontrol & 0,67 & 18 & 0,907 & 0,66 \\
\hline Intervensi & 1,33 & 18 & 0,767 & \\
\hline
\end{tabular}

Sumber: Data Primer, 2021

Dari tabel 2 didapatkan hasil ratarata skor pola defekasi pada kelompok intervensi lebih tinggi yaitu sebesar 1,33 sedangkan kelompok kontrol adalah 0,67 , artinya kelompok kontrol lebih berisiko mengalami konstipasi dibandingkan dengan kelompok intervensi. Hasil analisis data perbedaan skor pola defekasi kelompok kontrol dan intervensi adalah 0,66. Hasil penelitian ini sama dengan hasil penelitian yang dilakukan oleh Ikaristi, dkk. (2014) dan Setyani \& Theresia (2020), yang menyatakan bahwa terdapat perbedaan skor konstipasi pada kelompok kontrol dan intervensi setelah dilakukan massage abdominal.

Tabel 3. Pola Eliminasi Defekasi Kelompok Kontrol dan Intervensi Setelah Pemberian Intervensi Massage Abdominal di Ruang ICU RS Panti Rapih Yogyakarta

\begin{tabular}{lcccc}
\multicolumn{2}{c}{$(\mathrm{n}=36)$} & & \\
\hline & \multicolumn{2}{c}{ Kelompok Kontrol } & \multicolumn{2}{c}{ Kelompok Intervensi } \\
\cline { 2 - 5 } & $\mathrm{n}$ & $\%$ & $\mathrm{n}$ & $\%$ \\
\hline Konstipasi & 11 & 30,6 & 3 & 8,3 \\
Berisiko mengalami konstipasi & 2 & 5,6 & 6 & 16,7 \\
Tidak Konstipasi & 5 & 13,9 & 9 & 25 \\
Total & 18 & 50 & 18 & 50 \\
\hline
\end{tabular}

Sumber: Data primer, 2021

Dari tabel 3 menunjukkan bahwa kelompok kontrol sebanyak 30,6\% mengalami konstipasi, hal ini disebabkan oleh faktor mobilisasi pasien pasif dan adanya penggunaan sedative. Adapun tindakan keperawatan yang dilakukan untuk penanganan konstipasi antara lain merubah posisi pasien 2 jam sekali, perawat melakukan kolaborasi dengan ahli gizi untuk pemberiaan diit untuk menangani konstipasi. Sedangkan pada kelompok intervensi (tindakan standar dan abdominal massage), hasilnya menunjukkan bahwa mayoritas tidak mengalami konstipasi yaitu sebanyak $25 \%$.

Tabel 4. Uji Normalitas Skor Pola Eliminasi Defekasi

Responden Kelompok Kontrol dan Intervensi di Ruang ICU RS Panti Rapih Yogyakarta

$$
(\mathrm{n}=36)
$$




\begin{tabular}{|c|c|c|c|c|}
\hline \multirow{2}{*}{$\begin{array}{l}\text { Pola } \\
\text { defekasi }\end{array}$} & \multirow[t]{2}{*}{ Kategori tindakan } & \multicolumn{3}{|c|}{ Shapiro-Wilk } \\
\hline & & Statistic & Df & Sig. \\
\hline & Kontrol & 0,671 & 18 & 0,000 \\
\hline & Intervensi & 0,767 & 18 & 0,001 \\
\hline \multicolumn{5}{|c|}{\begin{tabular}{lll} 
Uji normalitas data skor pola eliminasi & \multicolumn{3}{l}{ data tersebut berdistribusi tidak normal, } \\
defekasi kelompok kontrol dan kelompok & sehingga untuk mengetahui pengaruh \\
intervensi menggunakan Shapiro-Wilk, & massage abdominal terhadap pola \\
karena sampel 36 responden. Hasil uji & eliminasi defekasi menggunakan uji \\
normalitas data didapatkan p-value= & analisisMann-Whitney. \\
0,000 dan $0,001(\mathrm{p}<0,05)$, artinya bahwa &
\end{tabular}} \\
\hline \multicolumn{5}{|c|}{$\begin{array}{l}\text { Tabel 5. Pengaruh Massage Abdominal Terhadap Pola Defekasi } \\
\text { di Ruang ICU Rumah Sakit Panti Rapih Yogyakarta }\end{array}$} \\
\hline \multicolumn{5}{|c|}{ Skor pola eliminasi defekasi } \\
\hline \multicolumn{2}{|c|}{ Mann-Whitney $U$} & \multicolumn{3}{|c|}{96.000} \\
\hline \multicolumn{2}{|c|}{$\mathrm{Z}$} & \multicolumn{3}{|c|}{-2.236} \\
\hline \multicolumn{2}{|c|}{ Asymp. Sig. (2-tailed) } & \multicolumn{3}{|c|}{0,025} \\
\hline
\end{tabular}

Berdasarkan tabel 5 menujukkan bahwa hasil uji statistik menggunakan Mann-Whitney didapatkan p-value 0,025 sehingga dapat disimpulkan bahwa ada pengaruh massage abdominal terhadap pola defekasi pada pasien yang dirawat di ruang ICU RS Panti Rapih Yogyakarta. Hasil penelitian ini sesuai dengan penelitian Ikaristi, dkk (2014), yang menyatakan bahwa terdapat perbedaan skor konstipasi pada kelompok kontrol dan intervensi. Berdasarkan hasil analisis data skor konstipasi menunjukkan bahwa kelompok kontrol, rata-rata skor konstipasi adalah 3,22 sedangkan pada kelompok intervensi rata-rata skor konstipasi adalah 2,17. Hasil analisis data perbedaan skor konstipasi pada kelompok kontrol dan intervensi menunjukkan $\mathrm{p}$ value 0,015 , artinya ada perbedaan skor konstipasi pada kelompok kontrol dan intervensi, sehingga dapat disimpulkan massage abdominal berdampak terhadap pencegahan konstipasi pada pasien yang dirawat di ruang ICU.

Menurut Estri, dkk, (2016), mengatakan bahwa Massage abdominal dengan teknik effleurage lebih efisien dalam waktu pelaksanaan, energi yang dikeluarkan lebih minimal, gerakan massage lebih sistematis dan mudah untuk diterapkan, serta memberikan efek kenyamanan. Massage abdominal dengan teknik effleurage dapat menjadi pilihan intervensi untuk pencegahan konstipasi pada pasien yang terpasang ventilasi mekanik. Hasil penelitian ini dapat dijadikan terapi komplementer yang dapat dikembangkan di tatanan keperawatan kritis serta dijadikan dasar penelitian lanjutan mengenai lamanya efek massage abdominal terhadap defekasi meskipun massage abdominal sudah dihentikan. Berdasarkan penelitian sebelumnya, tindakan massage abdominal terbukti efektif untuk mengatasi konstipasi terutama pada pasien yang dirawat di ruang ICU.

Pasien di ICU dengan rata-rata berusia lanjut usia, aktivitas pasien dengan mobilisasi pasif, pasien dengan diagnosa medis gagal nafas, terpasang alat ventilasi mekanik, mendapat terapi sedativa dan pemberian analgetika narkotika yang mempunyai resiko terjandinya konstipasi karena penurunan kerja motilitas usus.

Hasil penelitian ini rata-rata skor pola defekasi pada kelompok intervensi yaitu sebesar 1,33 lebih tinggi dibandingkan dengan pola defekasi pada kelompok kontrol, yaitu sebesar 0,67. Hasil analisis data perbedaan skor pola defekasi pada kelompok kontrol dan intervensi menunjukkan $\mathrm{p}$ value 0,025 , hal ini menunjukkan bahwa ada pengaruh pemberian massage abdominal terhadap 
rata-rata pola defekasi pasien yang sedang dirawat di Ruang ICU, hal tersebut membuktikan bahwa tindakan komplementer berupa massage abdominal efektif untuk mengatasi masalah konstipasi pada pasien yang sedang dirawat di ICU.

\section{KESIMPULAN}

a. Pola eliminasi defekasi pada kelompok kontrol yaitu $30,6 \%$ mengalami konstipasi, $5,6 \%$ berisiko konstipasi dan $13,9 \%$ tidak konstipasi.

b. Pola eliminasi defekasi pada kelompok intervensi yaitu sebesar $8,3 \%$ mengalami konstipasi, 16,7\% berisiko konstipasi dan $25 \%$ tidak konstipasi

c. Ada pengaruh massage abdominal terhadap pola eliminasi defekasi pada pasien yang dirawat di Ruang ICU RS Panti Rapih Yogyakarta $(p<0,05)$

\section{SARAN}

a. Perawat diharapkan mampu melakukan tindakan massage abdominal secara konsisten dan teratur selama tidak ada kontraindikasi.

b. Rumah Sakit memberikan sarana dan fasilitas untuk mengimplementasikan terapi komplementer massage abdominal untuk menjaga keteraturan pola eliminasi defekasi pasien di Ruang ICU.

\section{UCAPAN TERIMAKASIH}

Penulis mengucapkan terima kasih yang sebesar-besarnya kepada semua pihak yang membantu dan terlibat dalam penelitian ini, terutama STIKes Panti Rapih Yogyakarta dan juga para responden.

\section{REFERENSI}

Azevedo, R. P. D., \& Machado, F. R. 2013. Constipation in critically ill patient: much more than image. Revista Brasileira de terapia intensiva, 25(2), 73-74. https://doi.org/10.5935/0103507X.20130014

Estri, A. K, Fatimah, S., \& Prawesti, A. 2016. Perbandingan Abdominal Massage dengan Teknik Swedish Massage dan Teknik Efflurage terhadap Kejadian Konstipasi pada Pasien yang Terpasang Ventilasi Mekanik di ICU. JurnalKeperawatan Padjajaran, 4 (3).

Hasmi, H., Waluyo, A., \& Ohorella, U. B. 2020. The Beneficial Effects of Abdominal Massage on Constipation and Quality of Life: A Literatur Review. Indonesian Contemporary Nursing Journal, 4(2), 72-82. https://doi.org/10.20956/icon.v4i2.919 3

Kahraman, B. B., \& Ozdemir, L. 2015. The impact of abdominal massage administered to intubated and enterally fed patients on the development of ventilator-associated pneumonia: a randomized controlled study.

International journal of nursing studies, 52(2),

519-524.

https://doi.org/10.1016/j.ijnur stu.2014.11.001

Lamas, K., Lindholm, L., Stenlund, H., Engstrom, B., \& Jacobsson, C. 2009. Effects of abdominal massage in management of constipation-a randomized controlled trial. International journal of nursing studies, 46(6), 759-767. https://doi.org/10.1016/j.ijnur $\underline{\text { stu. 2009.01.007 }}$

LeMone, P., Burke, K. M., \& Bauldoff, G. 2016. Buku ajar keperawatn medikalbedah. Jakarta: EGC.

Priscilla, L., Karen, B., Gerene, B. 2016. Buku ajar: Keperawatan medikal bedah. (Vol 2) (Ed 5). Jakarta: EGC

Sari, R.F., Fauzan, S., dan Budiharto, I. 2015. Pengaruh Open Suction Terhadap Tidal Volume Pada Pasien yang Menggunakan Ventilatr di Ruang ICU dr.Soedarso Pontianak. Jurnal Kesehatan Khatulistiwa. https://jurnal.untan.ac.id. Penerbit Buku Kedokteran EGC. Jakarta 
Setyani, F. A. R., \& Theresia, S. I. M. 2020. Pengaruh Abdominal Massage

Dalam Upaya Pencegahan Konstipasi pada Lanjut Usia di BPSTW Abiyoso Yogyakarta. Jurnal Kesehatan Kusuma Husada, 205-211. DOI: $\quad$ https://doi.org/10.34035/j k.v11i2.453

Theresia, S. I. M., Setyani, F. A. R., \& Estri, A. K. Pengaruh Massage Abdominal dalam Upaya Pencegahan Konstipasi pada Pasien yang Menjalani Rawat Inap Di Rumah Sakit Panti Nugroho Yogyakarta. Jurnal Akper Panti Rapih Yogyakarta. http://stikespantirapih.ac.id/download/ MANUSKRIP\%20B U\%20SIWI.pdf

Smeltzer ， S.C. 2013. Keperawatan Medikal Bedah. Handbook for Brunner \& Suddarth's Textbook of Medical-Surgical Nursing).

Sinclair, M. 2011. The use of abdominal massage to treat chronic constipation. Journal of bodywork and movement therapies, 15(4), 436-445. https://doi.org/10.1016/j.jbmt.2010.07. $\underline{007}$

Vincent, J.L, Preiser,J.C.2015. Getting critical about constipation. Journal Practical Gastroenterology. Nutrition Issues in Gastroenterology, Series 144, 14-25. https://med.virginia.edu/ginut rition/wp-content/uploads/site s/199/2014/06/Parrish-August -15.pdf 